\title{
Duygu analizi ve yapay sinir ağı kullanılarak envanter rotalama problemi için talep tahmini
}

\author{
Demand forecasting for inventory routing problem using artificial neural network and \\ sentiment analysis
}

\author{
Aslı BORU İPEK ${ }^{1, a}$, Ayşe Tuğba DOSDOĞRU*1,b, Rızvan EROL ${ }^{2 c}$ \\ ${ }^{1}$ Adana Alparslan Türkeş Bilim ve Teknoloji Üniversitesi, Mühendislik Fakültesi, Endüstri Mühendisliği Bölümü, 01250, Adana \\ ${ }^{2}$ Çukurova Üniversitesi, Mühendislik Fakültesi, Endüstri Mühendisliği Bölümü, 01330, Adana
}

• Geliş tarihi / Received: 20.02.2020 • Düzeltilerek geliş tarihi / Received in revised form: 25.11.2020 • Kabul tarihi / Accepted: 02.12.2020

\section{$\ddot{O} z$}

Sosyal medya kullanıcılarının sayısı her geçen gün katlanarak artmaktadır. Bu gelişme, tedarik zincirinde iş zekasının ilerletilmesinde önemli firsatlar sunduğu için araştırmacıları ve yöneticileri sosyal medya ve müşteri duygularını analiz etmeye teşvik etmektedir. Ancak, tedarik zinciri üyeleri günümüz iş dünyasında genel duyguları anlamakta zorlanmaktadır. $\mathrm{Bu}$ nedenle, tedarik zincirine değerli bilgiler sağlamak için çeşitli yöntemler kullanılmaktadır. Bu çalışmada, SentiStrength tek bir ürün ile ilgili müşteri yorumlarını analiz etmek için kullanılmaktadır. Daha sonra, SentiStrength'in çıktısı ve ürün talepleri, müşteri taleplerini tahmin etmek için Yapay Sinir Ağına beslenmiş̧ir. Ardından, tahmin edilen müşteri talepleri kullanılarak envanter rotalama problemini çözmek için Baskılanamayan Sıralamalı Genetik Algoritma II (NSGA-II) tabanlı simülasyon optimizasyonu kullanılmıştır. Çalışmanın sonuçları, duygu analizi içeren melez metodolojinin kullanımının envanter rotalama problemini başarılı bir şekilde analiz edebileceğini göstermiştir.

Anahtar kelimeler: Duygu analizi, Envanter rotalama problemi, Simülasyon optimizasyonu

\begin{abstract}
Social media users have been growing exponentially in recent years. This growth has evoked researchers and manager to analyze the social media and customer sentiment because it offers significant opportunities to advance business intelligence in supply chain. However, supply chain members are struggling in understanding the general sentiments in today's business world. Therefore, various methods are used to provide valuable insights in supply chain. In this paper, SentiStrength is used to analyze customer reviews related to one type of product. The output of SentiStrength and demands of the product are then fed into Artificial Neural Network to forecast the customer demands. After, nondominated sorting genetic algorithm II (NSGA-II) based simulation optimization is employed to solve the inventory routing problem using forecasted customer demands. The results of the study demonstrated that the use of hybrid methodology containing sentiment analysis can successfully analyze the inventory routing problem.
\end{abstract}

Keywords: Sentiment analysis, Inventory routing problem, Simulation optimization

\footnotetext{
*b Ayşe Tuğba DOSDOĞRU; adosdogru@atu.edu.tr, Tel: (0322) 455-0000, orcid.org/0000-0002-1548-5237

a orcid.org/0000-0001-6403-5307 c orcid.org/0000-0001-6914-5062
} 


\section{Giriş}

Günümüzde sosyal ağlar aracıllğıyla birçok bilgi paylaşımı yapılmaktadır. İnsanlar fikirlerini ve duygularını sosyal medya siteleri, forumlar ve bloglar aracılığıyla paylaşabilmektedir. Özellikle çevrimiçi sosyal medya web siteleri temel bilgilerin üretimini, iletimini ve tüketimini sağlamaktadır. Tüketiciler ve üreticiler arasında bağlantı sağlamak için sosyal medya başarıyla kullanılmaktadır. Sosyal medya binlerce kişiye anket yapılmadan önemli bulgulara ulaşmayı mümkün kılmaktadır. Örneğin, Twitter milyonlarca insanı ağ üzerinden birbirine bağlamaktadır. Sosyal medya, işletmeler için ürünle ilgili geri bildirim ve ürünün daha iyi nasıl geliştirilebileceği konusunda fikir sahibi olmaları için harika bir firsat sunmaktadır. Ayrıca işletmelerin müşterileriyle doğrudan etkileşime girmeleri için yeni firsatlar sağlamaktadır (Gaikar ve Marakarkandy, 2015).

Özellikle ürün yorumları, işletmelerin pazar araştırması için kullandığı anahtar kaynaklardan biridir. İşletmeler, ürün yorumlarını yakından izleyerek pazar hakkında bilgi edinebilirler. Diğer yandan, hacimli ve dinamik yapısı nedeniyle tüketici tarafından sağlanan çevrimiçi yorumların analizi zor olabilir. Ürün yorumlarının çoğu, yalnızca ürün ile ilgili görüşlerin sayısal derecelendirmelerini değil, aynı zamanda metinsel içeriği de içermektedir (Schneider ve Gupta, 2016). $\mathrm{Bu}$ nedenle, bu verilerden anlamlı bilgileri elle çıkarmak zordur. Ayrıca, işletmelerin ürünler hakkındaki fikirlerini özetlemesi ve analiz etmesi de zorlu bir süreçtir. İnternet ortamı çok fazla bilgi içermektedir, ancak fazla bilgi, doğru bilgiye ulaşmayı karmaşık ve zor hale getirebilmektedir. Örneğin, sosyal medya kullanıcısının restoran gibi bir yer hakkındaki yüzlerce yorumu okuması ve yorumlaması zahmetli bir süreçtir. Bu nedenle, duygu analizi kullanılmadığında insanların duygu ve düşüncelerini değerlendirmek uzun zaman alabilir.
Duygu analizi, verilerin analiz sürecidir ve çevrimiçi alışveriş verilerini başarıyla analiz etmek için kullanılabilir. Çevrimiçi alışveriş siteleri çok fazla ürün yorumu içermektedir. Bir ürünü satın almadan önce, müşteriler o ürünle ilgili yorumları okuyarak karar verebilmektedirler. Diğer insanların görüşleri, bir tür doğal dil işleme görevi olan duygu analizi ile kolayca analiz edilebilmektedir. Duygu analizi, insanların belirli bir konu hakkındaki görüşlerini sınıflara ayırmaktadır (Rani ve Singh, 2017). Duygu analizinde, metin polaritesi genellikle pozitif, negatif ve nötr olmak üzere üç sınıfa ayrılmaktadır.

Günümüzde tedarik zinciri yönetimi, rekabet avantajlarını korumak ve müşteri taleplerini karşılamak için birçok firma tarafindan uygulanmaktadır. Tedarik zinciri yönetimi, tedarik zincirindeki tüm süreçleri içermektedir. Dağıtım süreci de bu süreçlerden biridir. Dağıtım süreci, ulaştırma ve envanter yönetiminden doğrudan etkilenmektedir. Ancak, ulaşım ve envanter yönetimi modelleme yaklaşımlarında genellikle bağımsız olarak ele alınmaktadır. Bu nedenle, karşılıklı etkileri genellikle ihmal edilmektedir. Envanter yönetimi ve ulaştırma arasındaki ilişkiyi analiz etmek için, bu iki faaliyet aynı anda düşünülebilir. $\mathrm{Bu}$ da literatürde ERP olarak ele alınmaktadır. $\mathrm{Bu}$ problemde amaç, envanter yönetimi ve araç rotalamasının toplam maliyetini en aza indirmektir. Problem karmaşıklığ 1 , envanter yönetimi ve rotalamanın aynı anda değerlendirilmesi ile ilgilidir (Popović vd., 2012). $\mathrm{Bu}$ çalışmada, Envanter Rotalama Problemi (ERP)'ne yeni bir metodoloji önermek amaciyla duygu analizi kullanılmıştır. Tasarlanan metodoloji iki aşamadan oluşmaktadır. Aşama I'de müşteri yorumlarının skorunu hesaplamak için SentiStrength kullanılmıştır. Daha sonra, SentiStrength çıktısı ve gerçek müşteri talepleri Yapay Sinir Ăg (YSA) ile entegre edilmiştir. Aşama II'de ERP'yi çözmek için YSA çıktısı (yani, tahmin edilen müşteri talepleri), NSGA-II tabanlı simülasyon optimizasyonu (SO)'na beslenmiştir. Önerilen metodolojinin genel yapısı Şekil 1'de verilmiştir.

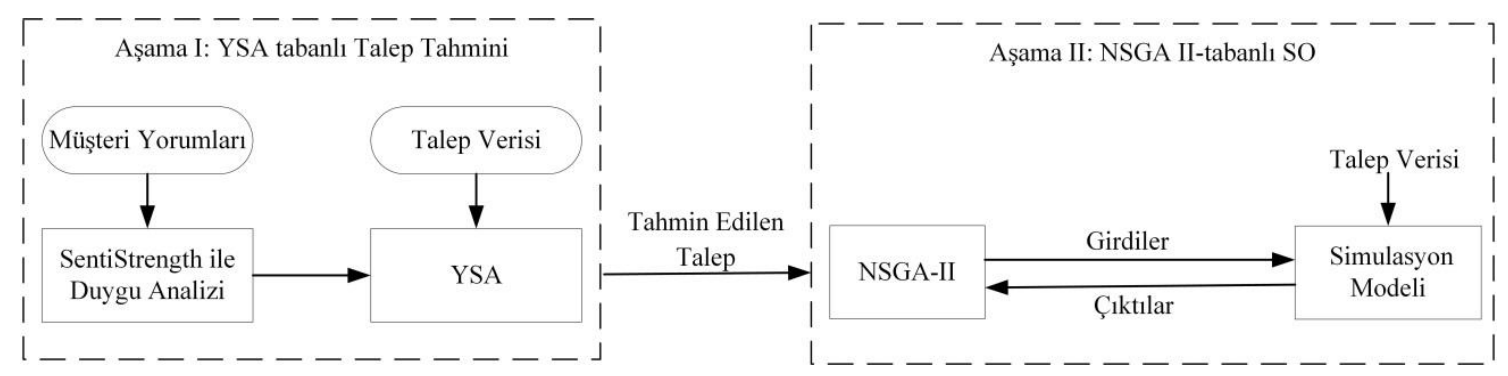

Şekil 1. Önerilen metodolojinin genel yapısı 


\section{2. Önceki çalışmalar}

Ürünlerin gelecekteki satış performans1, müşteri değerlendirmelerinden elde edilen duygulardan ve değerlendirmelerin kalitesinden önemli ölçüde etkilenmektedir (Balaji, 2015). Bu nedenle, müşteri değerlendirmeleri, satışlar üzerinde kritik bir etkiye sahip olabileceğinden tahminleme modelleriyle entegre edilebilir. Örneğin, Yu vd. (2012) çalışmalarında satış tahmini için duygu analizi içeren bir metot tasarlamışlardır. Ayrıca, yorumların duygu analizi için olasılıksal model kullanılmıştır. Film sektöründen gerçek bir örnek kullanılarak yorumlar arasındaki ilişki araştırılmıştır. Sonuçlar, önerilen yöntemin otoregresif modeline kiyasla daha iyi tahmin performansı verdiğini göstermiştir.

Gaikar ve Marakarkandy (2015) çalışmalarında ürünün satın alınmasını etkileyen faktörleri belirlemişlerdir. Çalışmada, API kullanılarak Twitter'dan film hakkında tweet'ler toplanmıştır. Pozitif ve negatif tweet'leri belirlemek için duygu analizi aracı kullanılmıştır. Jadav ve Vaghela (2016) optimize edilmiş Destek Vektör Makinesi'ni (DVM) kullanmışlardır. Önerilen modelin performansını karşılaştırmak için Naïve Bayes ve DVM kullanılmıştır. Çalışmada, yapılandırılmamış film yorumları önce yapılandırılmış forma dönüştürülmüş ve daha sonra önerilen yöntemler için girdi olarak kullanılan skor hesaplanmıştır. Dey vd. (2016) çalışmalarında Naïve Bayes ve ken yakın komşu dahil olmak üzere iki denetimli makine öğrenme algoritması kullanmışlardır. Çalışmada önerilen algoritmalar, film yorumları ve otel yorumları için kullanılmıştır. Ahn ve Spangler (2014) sosyal medya tabanlı özellikleri dikkate alarak satış tahminlerinin performansını analiz etmişlerdir. Aylık otomobil satışlarını modellemek için otoregresif entegre hareketli ortalama kullanılmıştır. Schneider ve Gupta (2016) satış tahmin modelindeki boyutu azaltmak için rastgele projeksiyon modeli kullanmışlardır. Ayrıca, önerilen modelin sonuçlarını karşılaştırmak için DVM kullanılmıştır. Fan vd. (2017) çalışmalarında Bass ve Norton modelini ürün satış tahminleri için çıkarılan duygu endeksi ile birleştirmişlerdir. Çevrimiçi yorumları sınıflandırmak için Naive Bayes, DVM ve k-en yakın komşu kullanılmıştır. Önerilen modelin performansını değerlendirmek için otomotiv endüstrisinden veriler kullanılmıştır. Lau vd. (2018), paralel yön odaklı duygu analizi içeren büyük veri analizi metodolojisi tasarlamışlardır. Buna ek olarak, duygu temelli satış tahminlerinde paralel evrimsel aşırı öğrenme makinesi kullanmışlardır.
Pai ve Liu (2018) aylık toplam araç satışlarını tahmin etmek için hem zaman serisi modellerini hem de çok değişkenli regresyon modellerini kullanmışlardır. Satışları tahmin etmek için iki kategori kullanılmıştır. Birinci kategoride, veri kümesi olarak geçmiş aylık toplam araç satışları kullanılmış, ikinci kategoride ise tweetlerin duygu skorları ve iki borsa değeri yer almıştır. Çalışmada satışları tahmin etmek için mevsimsellikten arındırma yöntemleri de uygulanmıştır. Kumar vd. (2016) çalışmalarında Naïve Bayes, Lojistik Regresyon ve SentiWordNet algoritmas1 ile yorumları olumlu ve olumsuz olarak sınıflandırmışlardır. Çalışmada yorumlar, Amazon web sitesinden alınmıştır.

Duygu analizi uygulamaları, birçok alanda kullanılmaktadır. Örneğin, Deniz ve Kızıloz (2017) çalışmalarında Türkçe belgelerin yazar, tür ve cinsiyet açısından metin sinıflandırmasını ele almışlardır. Gezici ve Yanıkoğlu (2018), film değerlendirmelerinin Türkçe sınıflandırılmasında farklı özelliklerin etkinliğini araştırmışlardır. Ozturk vd. (2017) çalışmalarında öğrencilerin sosyal medyada Anadolu Üniversitesi'ne yönelik düşüncelerini anlamak için Twitter kullanmışlardır. Çalışmada, toplanan tweet'ler pozitif, negatif ve nötr olmak üzere üç duygu sınıfında sınıflandırılmıştır. Swain ve Cao (2019) çalışmalarında tedarik zinciri üyeleri tarafından üretilen sosyal medya içeriğinin tedarik zinciri performansı üzerindeki etkisini analiz etmişlerdir. Duygu analizi, önerilen hipotezleri test etmek için Naive Bayes aracıllğıyla uygulanmıştır. Çalışmanın sonuçları, sosyal medya içeriğinin tedarik zincirinde bilgi paylaşımı ve işbirliği için faydalı olabileceğini göstermiştir. Çalışmamızın ana katkıları şu şekilde özetlenebilir: (i) Müşteri yorumlarının duygu skorunu hesaplamak için SentiStrength uygulanmasi; (ii) Müşteri talebini tahmin etmek için YSA'nın duygu skoru ile birlikte uygulanması; (iii) Talep tahminlerinin kullanıldığı ERP'yi çözmek için NSGA-II tabanlı SO'nun uygulanmasıdır.

\section{Materyal ve yöntem}

Bu çalışmada Amazon web sitesinde yer alan elektronik ile ilgili müşteri yorumları, yapılandırılmamış ürün bilgileri olarak kullanılmıştır. SentiStrength, İngilizce metinden duygu skorunu belirlemek için kullanılmıştır. SentiStrength, kısa, resmi olmayan İngilizce metinde duygu skorunu bulmak için ek dil bilgisi ve kuralları kullanan sözlük tabanlı bir siniflandiricidır (Thelwall vd., 2012). SentiStrength, pozitif ve negatif duygu skorunu 
aynı anda belirlemektedir. SentiStrength çıktısı her metin için iki tamsayı içerir. Birinci tamsayı, duygu skoru +2 ile +5 arasında olan pozitif duygu, diğeri ise duygu skoru -2 ile -5 arasında değişen negatif duyguyu belirtmektedir (Thelwall vd., 2012). Nötr kelimeleri belirtmek için \pm 1 kullanılmaktadır.

SentiStrength metni kelimelere böler ve duygu skorunu belirlemek için her kelime kontrol edilir. Cümlenin genel skoru, en yüksek pozitif ve negatif puan dikkate alınarak belirlenir. Müşteri yorumlarında birden fazla cümle bulunduğunda, her cümlenin maksimum puanı alınır. Örnek müşteri yorumunun değerlendirilmesi Tablo 1'de verilmektedir. Bu metinde, maksimum pozitif (pz) skor 3 ve maksimum negatif (ng) skor -1'dir.

Çalışmamızda, büyük verilerin hacmini ve çeşitliliğini sağlamak amacıyla Amazon web sitesinin elektronik kategorisinde yer alan tüm müşteri yorumları filtrelenmiş ve daha sonra bir yı1 boyunca müşteri yorumları veri kümesi olarak saklanmıştır. Müşteri yorumlarına ek olarak, Chen vd. (2012)'nin çalışmalarında kullandıkları müşteri talep verileri kullanılmıştır. Kullanılan veri seti, satıcı tarafından tutulan müşteri ile ilgili 11 farklı değişkeni içeren verileri içermektedir. $\mathrm{Bu}$ değişkenler, 2010 ve 2011 yıllarında gerçekleşen tüm işlemleri içermektedir.

Tablo 1. Örnek müşteri yorumunun değerlendirilmesi

\begin{tabular}{llll}
\hline Müssteri Yorumu & Pz & Ng & Cümlelerin değerlendirilmesi \\
\hline $\begin{array}{l}\text { What can I say, it's a Nikon lens cap. } \\
\text { Good quality as expected. I love }\end{array}$ & -1 & What can I say, it's a Nikon [proper noun] lens cap. \\
$\begin{array}{l}\text { Goon } \\
\text { these caps with the spring action } \\
\text { releases. }\end{array}$ & & [sentence: 1,-1] \\
\end{tabular}

Ele alınan tedarik zincirinde müşteri talebini tahmin etmek için YSA kullanılmıştır. YSA modelinde veri kümesi, eğitim seti $(\% 80)$ ve test seti (\% 20) olarak ayrılmıştır. Yorumlardan elde edilen duygu skorlarına ve talep değerlerine YSA öncesi önişleme işlemi olarak normalleştirme uygulanmıştır. Denklem (1) kullanılarak veri kümesi $[0,1]$ aralığında normalleştirilmiştir.

$$
y=\frac{x-\text { minimum }}{\text { maksimum }- \text { minimum }}
$$

Burada $x$, gözlemlenen değerler kümesini, minimum ve maksimum sırasıyla gözlemlenen değerler kümesindeki minimum ve maksimum değerleri belirtmektedir.

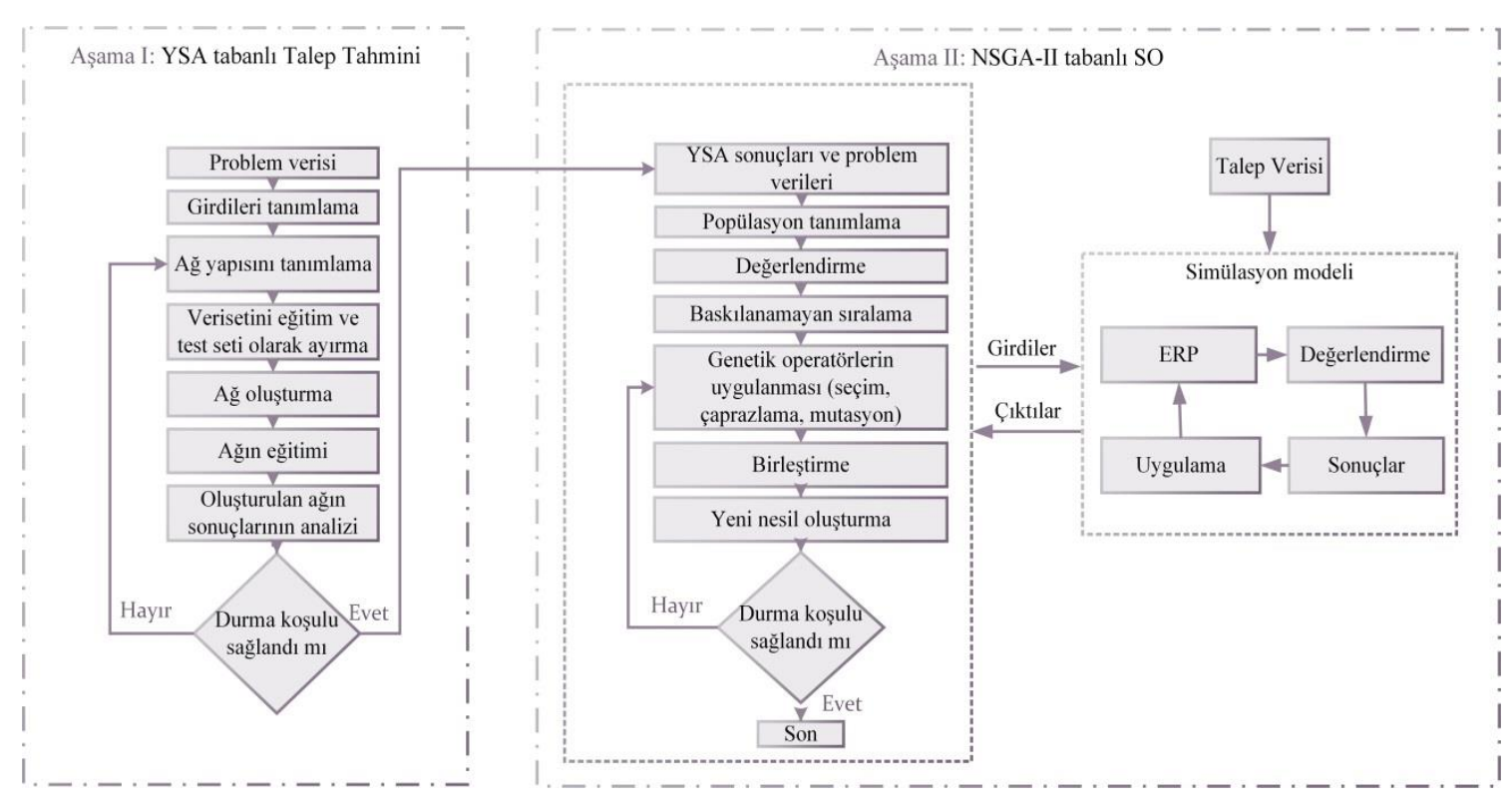

Şekil 2. Tasarlanan yöntem

Tasarlanan YSA üç katmandan oluşmaktadır. İlk katman giriş katmanıdır. İkinci katman 20 gizli nöron içeren gizli katmandır. Son katman çıktı katmanıdır. YSA parametreleri deneme yanılma yöntemiyle belirlenmiştir. Bu çalışmada, amaç fonksiyonu olarak ortalama karesel hata (MSE) seçilmiştir. Optimizasyon metodu için "adam" seçilmiştir. Aktivasyon fonksiyonu olarak 
doğrultulmuş doğrusal birim (ReLU) kullanılmıştır. Tahmin edilen müşteri talepleri kullanılarak, tedarik zincirindeki ERP'yi çözmek için SO yöntemi oluşturulmuştur (Şekil 2).

$\mathrm{Bu}$ çalışmada, tedarik zinciri beş müşteri ve beş Dağıtım Merkezi (DM) içermektedir. Her müşteri talebi farklı DM tarafından karşılanmaktadır. Her bir DM'nin envanter kontrolü periyodik gözden geçirme (s, S) politikası dikkate alınarak yapılmaktadır. Envanter belli periyotlarla (R, inceleme periyotu) kontrol edilmektedir. Çalışmamızda $\mathrm{R}$ sabit ve 5 gün olduğu varsayılmıştır. Eğer stok miktarı yeniden sipariş noktasında (s) ya da altında ise belli miktarda sipariş verilerek stok miktarı maksimum sipariş miktarı seviyesine (S) ulaştırılmaktadır. Eğer stok seviyesi yeniden sipariş noktasının üzerinde ise sipariş verilmemektedir. SO modeli üç ay boyunca çalıştırılmıştır.

Çalışmamızda, toplam tedarik zinciri maliyeti (TTZM) ve DM'lerinin servis seviyelerinin ortalaması dikkate alınarak araç için rota belirlenmektedir. Araç, tedarikçiye geri dönerken en kısa yolu kullanmaktadır. Çalışmamızda kapasite sınırı olmayan tek araç kullanılmış ve bu aracın hızının düzgün $(80,90)$ metre/saat dağıldığı varsayılmıştır. Her bir inceleme periyodunda her bir DM en fazla bir kez ziyaret edilmektedir. Yenileme siparişine bağlı olarak her DM'ye teslim edilen miktar değişiklik göstermektedir. Rotalama maliyeti Denklem (2) kullanılarak hesaplanmaktadır.

$V(s, S)=\tau+\sum_{d=1}^{\text {toplam teslimat saylst }} \gamma_{d}+\sum_{i \in S\{d\}}\left(\vartheta_{i}+\alpha\right.$ Dist $\left._{i j}\right)$

$\tau$, aracın maliyetidir. $\gamma_{d}$ ise dağıtımın başlaması için gerekli olan sabit maliyettir. $\vartheta_{i}$, her müşteride duraklamasının sabit maliyetidir. Birim mesafedeki ulaşım maliyeti ise $\alpha$ 'dır. Her dağıtım merkezinden Tedarikçiye olan uzaklık Dist $_{i j}$ ile ifade edilmektedir. Son olarak $S\{d\}$, mevcut dağıtım merkezlerini ifade etmektedir.

TTZM, rotalama maliyeti $(V(s, S))$ ve envanter maliyetini $E M(s, S))$ içermektedir (Denklem (3)).

$\mathrm{TTZM}=E M(s, S)+V(s, S)$

$E M(s, S)=\sum_{n=1}^{\text {Toplam Periyot }}\left\{\sum_{\mathrm{i}=1}^{\mathrm{I}}\left(\mathrm{h}_{\mathrm{i}} \mathrm{X}_{\mathrm{in}}^{+}+\mathrm{I}\left\{\mathrm{X}_{\mathrm{in}} \leq \mathrm{s}\right\}\left(\mathrm{k}_{\mathrm{i}} \mathrm{X}_{\mathrm{in}}^{-}+p_{i} P_{i}+c_{i}+O_{i}\right)\right)\right\}$

Denklem (4)'te $i$ DM sayısını, $n$ ise periyot sayısını ifade etmektedir. Çalışmamızda elde bulundurma maliyeti $\left(\mathrm{h}_{\mathrm{i}} \mathrm{X}_{\mathrm{in}}^{+}\right)$periyot boyunca elimizde bulunan envanter miktarı ile doğru orantılıdır. Elde bulundurmama maliyeti $\left(\mathrm{k}_{\mathrm{i}} X_{\text {in }}^{-}\right)$ise periyot boyunca karşılanamayan müşteri sipariş miktarı ile doğru orantılıdır. İşlem maliyeti $\left(p_{i} P_{i}\right)$ işlem süresi ile orantılıdır. Kullanım başına düşen sipariş maliyeti $\left(c_{i}\right)$ ise zamana bağlı olmaksızın dağıtım merkezleri kullanıldığında ele alınan bir maliyettir. Sipariş işleme maliyeti $\left(O_{i}\right)$ sipariş işleme süresine ve kullanım maliyetine göre ele alınmaktadır. TTZM parametrelerinin değerleri Boru vd. (2019) çalışmasında mevcuttur.

Yoğun rekabet koşullarında, marjinal kâr son yıllarda oldukça azalmıştır ve bu nedenle şirketlerin yönetim zorluklarının üstesinden gelebilmesi için toplam maliyeti düşürmesi gerekmektedir. ERP'de ortaya çıkan maliyetler, tedarik zincirinde hangi envanter rotalama modelinin kullanılacağına karar verilmesi aşamasında önemli bir rol oynamaktadır. Son yıllarda, çok amaçlı yöntemler tedarik zinciri optimizasyonunda daha yaygın hale gelmiştir. $\mathrm{Bu}$ yöntemler arasında NSGA-II, simülasyon tabanlı optimizasyon için en yaygın kullanılan algoritmadır (Avci ve Selim, 2017). NSGA-II, hızlı baskılanamayan sıralama prosedürü, seçkinci (elitist) koruyan yaklaşım ve parametresiz (parameter-free) paylaşım operatörü kullanarak diğer çok amaçlı genetik algoritma tabanlı yöntemlerden daha iyi performans göstermektedir (Deb et al., 2002). Bu nedenle, çalışmamızda optimizasyon yöntemi olarak SO modelinde kullanılmak için NSGA-II seçilmiştir. SO yönteminde, NSGA-II kullanılarak ortalama servis seviyesi en üst düzeye çıkarılırken toplam tedarik zinciri maliyeti en aza indirilmektedir. NSGA-II tabanlı SO modelinde iterasyon sayıs 20 olarak ele alınmıştır. Tasarlanan SO metodolojisinde, yeniden sipariş noktası, maksimum sipariş miktarı seviyesi ve başlangıç stoğu NSGA-II tarafından belirlenmektedir. NSGA-II, $\mathrm{O}\left(\mathrm{MN}^{2}\right)$ hesaplama karmaşıklığg ile hızlı baskılanamayan sıralama yaklaşımı sunmaktadır (Sarkar ve Modak, 2005). NSGA-II'de popülasyon, problem aralığı ve kısitlamalar dikkate alınarak tanımlanır. Baskılanamayan sıralama yaklaşımı uygulanır. Yığılma uzaklığı değeri hesaplanır. Bireylere 
genetik operatörler uygulanır. $\mathrm{Bu}$ işlemler, belirlenen sayıda nesil oluşturuluncaya kadar devam eder. NSGA-II ile ilgili detaylı bilgiler Deb et al. (2002) ve Yusoff vd. (2011) çalışmalarında mevcuttur. Ayrica, NSGA-II'nin uygulama prosedürü sözde kod (Konak vd., 2006) ile Şekil 3'te özetlenmektedir.

Adım 1: Boyutu $\mathrm{N}$ olan ebeveyn popülasyonunu $\left(P P_{0}\right)$ rassal oluştur. $t$ ise 0 olarak ayarlanır.

Adım 2: Boyutu $\mathrm{N}$ olan yavru popülasyonu $\left(Q P_{0}\right)$ oluşturmak için $P P_{0}$ 'a mutasyon ve çaprazlama uygulanir.

Adım 3: Durma kriteri karșılandığında $P P_{t}$ 'ye dönülür. t, nesil numarasını göstermektedir.

Adım 4: $P P_{t}$ ve $Q P_{t}$ içeren birleștirilmiş popülasyon $C P_{t}$ olarak atanır.

Adım 5: Hızlı baskılanamayan sıralama algoritması aracılığıyla $C P_{t}$ 'de baskılanamayan cepheler $\left(N D F_{1}, N D F_{2}, \ldots, N D F_{k}\right)$ tanımlanır.

Adım 6: Her $i=1, \ldots, k$ için aşağıdaki adımlar uygulanır.

Adım 6.1: $N D F_{i}$ 'deki her çözüm için yığılma uzaklığı hesaplanır.

Adım 6.2: $P P_{t+1}$ olușturulur.

Adım 7: $P P_{t+1}$ 'den ebeveynleri seçmek için yığılma uzaklığına dayalı seçim uygulanır. Boyutu $\mathrm{N}$ olan yavru popülasyon $Q P_{t+1}$ oluşturmak için $P P_{t+1}$ 'e mutasyon ve çaprazlama uygulanır.

Adım 8: $\mathrm{t}, \mathrm{t}+1$ olarak ayarlanır ve Adım 3'e geri dönülür.

Şekil 3. NSGA-II'nin sözde kodu (Konak vd., 2006)

\section{Bulgular ve tartışma}

İşletmelerin giderek karmaşıklaşan endüstriyel ortamlarda müşterilerin artan beklentilerini karşılamaları gerekmektedir. Veriler, tedarik zinciri sisteminin hammaddesidir ve veri kalitesi bir işletmenin durumunu belirler. İşletmeler, karar vermek için doğru verileri kullanmaya dikkat etmelidir. Bu noktada, çeşitli şekillerde üretilen ve toplanan veriler işletmeler için oldukça önemlidir. Büyük veriler, tedarik zincirinin analizinde önemli katkılar sunmaktadırlar. Birçok araştırmacı, tedarik zinciri yönetiminde büyük veri ve uygulama firsatlarını analiz etmeye, perspektif oluşturmaya ve geliştirmeye çalışmaktadır. Bununla birlikte, büyük verileri analiz etmek oldukça zordur. $\mathrm{Bu}$ çalışmada, her müşteri yorumu için duygu skorunun elde edilmesinde SentiStrength kullanılmıştır. Büyük verideki hacim ve çeşitliliği sağlamak için Amazon'daki elektronik ile ilgili müşteri yorumları kullanılmıştır. Her ne kadar nihai sonucu hesaplamak için farklı formlar mevcut olsa da, bu çalışmada ölçek çıktı formu kullanılmıştır. $\mathrm{Bu}$ formda sonuç, olumlu ve olumsuz duyguların toplamı olarak verilmiştir. Böylece, pozitif duygu ve negatif duygu skorları toplanmış ve nihai puan belirlenmiştir. Daha sonra, her gün için ortalama duygu skoru hesaplanmıştır. Yorumlar ile birlikte, tedarik zincirindeki müşteri talebini tahmin etmek için geçmiş müşteri talep verileri YSA'ya beslenmiştir. YSA'yı oluşturmak için tf.keras kullanılmıştır. YSA'nın yapısı Şekil 4 'te verilmiştir.

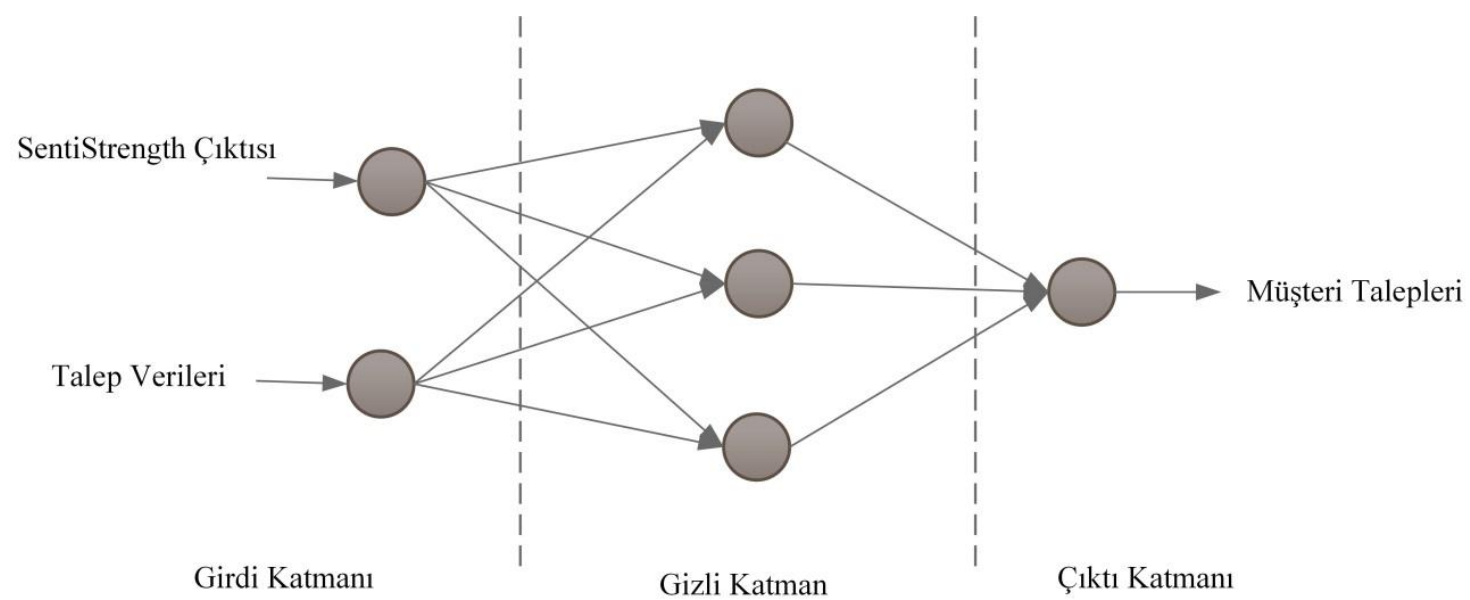

Şekil 4. YSA'nın yapısı 
Test setinin MSE değeri, her müşteri için Tablo 2'de verilmiştir. MSE değeri Denklem (5)'teki gibi hesaplanmıştır:

$$
\operatorname{MSE}=\frac{1}{n} \sum_{i=1}^{n}\left(e_{i}\right)^{2}
$$

Burada, $e_{i}=f_{i}-a_{i}$ şeklinde hesaplanmakta olup $f_{i}$ tahmin edilen talebi, $a_{i}$ ise gerçek talebi belirtmektedir.

YSA çıktısı, ERP'yi çözmek için NSGA-II tabanlı SO'ya beslenir. NSGA-II, seçilen karar değişkenlerine yeni değerler atamak için geliştirilmiştir. Her döngüde, simülasyon çıktısı NSGA-II'ye geri beslenir. Daha sonra bir kez daha NSGA-II, tasarlanan modelin performansını artırmak için daha iyi karar değişkenleri bulmaya çalışır. NSGA-II kullanılarak her bir DM için yeniden sipariş noktası, maksimum sipariş miktarı seviyesi ve başlangıç stoku belirlenir (Tablo 3). Tasarlanan NSGA-II'de popülasyon büyüklüğü 20, çaprazlama olasılığı 0.8 ve mutasyon olasıllı̆̆ 0.05 'tir. NSGA-II, C\# (Visual Studio Community 2017) kullanılarak kodlanmıştır. Simülasyon modeli Simio (Sürüm: 7.121.12363) kullanılarak geliştirilmiştir.

Tablo 2. Her müşteri için MSE değeri

\begin{tabular}{cc}
\hline Müşsteri & MSE \\
\hline Müşteri 1 & 0.01 \\
Müşteri 2 & 0.05 \\
Müşteri 3 & 0.11 \\
Müşteri 4 & 0.05 \\
Müşteri 5 & 0.03 \\
\hline
\end{tabular}

Tablo 3. Her bir tedarik zinciri üyesi için envanter kontrol parametrelerinin belirlenen optimal değerleri

\begin{tabular}{cccc}
\hline $\begin{array}{c}\text { Tedarik Zinciri } \\
\text { Üyesi }\end{array}$ & $\begin{array}{c}\text { Başlangıç } \\
\text { Stoku }\end{array}$ & $\begin{array}{c}\text { Yeniden Sipariş } \\
\text { Noktası }\end{array}$ & $\begin{array}{c}\text { Maksimum Sipariş Miktarı } \\
\text { Seviyesi }\end{array}$ \\
\hline DM1 & 603 & 403 & 1425 \\
DM2 & 658 & 371 & 1340 \\
DM3 & 1230 & 480 & 730 \\
DM4 & 1230 & 480 & 699 \\
DM5 & 1230 & 498 & 1164 \\
\hline
\end{tabular}

Tablo 4. Tedarik zinciri üyeleri için maliyet bileşeni analizi

\begin{tabular}{llccccc} 
& & $\begin{array}{c}\text { Elde } \\
\text { bulundurma } \\
\text { maliyeti }\end{array}$ & $\begin{array}{c}\text { Kullanım } \\
\text { başına düşen } \\
\text { sipariş maliyeti }\end{array}$ & $\begin{array}{c}\text { Elde } \\
\text { bulundurmama } \\
\text { maliyeti }\end{array}$ & $\begin{array}{c}\text { Sipariş̧ } \\
\text { işleme } \\
\text { maliyeti }\end{array}$ & $\begin{array}{c}\text { İşlem } \\
\text { maliyeti }\end{array}$ \\
\hline \multirow{2}{*}{ DM1 } & Maliyet (\$) & 5545 & 1283 & 0 & 1684 & 564 \\
& Yüzde değeri (\%) & 61 & 14 & 0 & 19 & 6 \\
DM2 & Maliyet \$ & 4818 & 1510 & 0 & 2058 & 953 \\
& Yüzde değeri (\%) & 52 & 16 & 0 & 22 & 10 \\
DM3 & Maliyet \$ & 7937 & 364 & 0 & 495 & 0 \\
& Yüzde değeri (\%) & 90 & 4 & 0 & 6 & 0 \\
DM4 & Maliyet \$ & 5062 & 976 & 0 & 1303 & 309 \\
& Yüzde değeri (\%) & 66 & 13 & 0 & 17 & 4 \\
DM5 & Maliyet \$ & 6381 & 917 & 0 & 1220 & 430 \\
& Yüzde değeri (\%) & 71 & 10 & 0 & 14 & 5
\end{tabular}

Tasarlanan yöntemde, toplam rotalama maliyeti 90010,83'tür. Ayrıca, diğer maliyet bileşenlerine ait sonuçlar da Tablo 4'te verilmektedir. Her tedarik zinciri üyesi için maliyet (\$) ve yüzde değeri (\%) tabloda verilmiştir. Genel olarak, maliyet bileşeninin en yüksek payı elde bulundurma maliyeti, maliyet bileşeninin en küçük pay1 ise elde bulundurmama maliyetidir. Her bir tedarik zinciri üyesi için miktar tabanlı ve sipariş tabanlı analiz yapabilmek amaciyla tamamen karşılanmış sipariş miktarı (TKSM) ve tamamen karşılanmış sipariş sayısı (TKSS) hesaplanmıştır. Örneğin, Tablo 5'te DM1 için TKSM, üç ay boyunca toplam karşılanan müşteri sipariş miktarını belirten 2487 birimdir. Ayrıca, DM1 için TKSS, üç ay boyunca toplam karş1lanan müşteri siparişi sayısını gösteren 17 sipariştir. Tüm müşteri talepleri tasarlanan yöntemle karşılansa da, karşılanan sipariş miktarı tedarik zinciri üyesine göre değişmektedir (Tablo 5). 
Tablo 5. Miktar tabanlı analiz ve sipariş tabanlı analiz

\begin{tabular}{ccc}
\hline Tedarik zinciri üyesi & TKSS & TKSM \\
\hline DM1 & 17 & 2487 \\
DM2 & 20 & 3284 \\
DM3 & 5 & 816 \\
DM4 & 13 & 1894 \\
DM5 & 12 & 2224 \\
\hline
\end{tabular}

\section{Sonuçlar}

Duygu analizi, işletmelerin tedarik zincirini geliştirmek için geri bildirim almalarını sağlayabilir. Ayrıca, işletmelerin müşteri yorumları yoluyla doğrudan müşterilerle etkileşim kurmaları için önemli firsatlar sunmaktadır. Müşteri yorumları, hizmetler ve ürünler hakkında birçok bilgi içermektedir. Olumlu yorumlar diğer müşterilerin satın alma istekliliğini etkileyebilir. Diğer yandan, olumsuz yorumların müşteriler üzerinde olumsuz bir etkisi olabilir. Bu çalışmada, ERP'yi çözmek için duygu analizi ve SO içeren yeni bir metodoloji tasarlanmıştır. Tasarlanan metodoloji, işletmelerin tedarik zincirini geliştirmeleri için yeni fursatlar sunmaktadır. Duygu analizi ve SO'nun entegrasyonu ERP'nin çözümüne yardımcı olur. Bu tür yöntemler, müşteri taleplerini etkili bir şekilde tahmin etmek için kullanılabilir. Müşteri yorumlarının kullanımı tedarik zinciri performansının artırılmasina da katkıda bulunmaktadır. Maliyet bileşeni analizine göre, tedarik zinciri üyeleri için elde bulundurmama maliyeti gözlenmemiştir. Günümüz dünyasında işletmelerin müşteri memnuniyetini artırabilmesi için elde bulundurmama durumunu ele almaları gerekmektedir. Bu çalışmanın sonuçları, tasarlanan metodoloji ile elde bulundurmama maliyetinin azaltılabileceğini göstermiştir. Gelecekteki çalışmalarda, duygu skorunu belirlemek için literatürde sıklıkla kullanılan DVM gibi makine öğrenmesi yöntemi kullanılabilir. Ayrıca, optimize edilmiş YSA kullanılarak sistemin performansı arttırılabilir.

\section{Teşekkürler}

$\mathrm{Bu}$ çalışma, Türkiye Bilimsel ve Teknolojik Araştırma Kurumu (TÜBİTAK) 2211-C Yurt İçi Öncelikli Alanlar Doktora Burs Program1 kapsamında desteklenmiştir.

\section{Kaynaklar}

Ahn, H.-I. and Spangler, W. S. (2014). Sales prediction with social media analysis. 2014 Annual Service
Research and Innovation Institute Global Conference (ss. 213-222). https://doi.org/10.1109/SRII.2014.37

Avci, M. G. and Selim, H. (2017). A multi-objective, simulation-based optimization framework for supply chains with premium freights. Expert Systems with Applications, 67, 95-106. https://doi.org/10.1016/j.eswa.2016.09.034

Balaji, S. M. E. (2015). Predicting sentiment analysis from online reviews. International Research Journal of Engineering and Technology, 2(9), 528-531.

Boru, A., Dosdoğru, A. T., Göçken, M. and Erol, R. (2019). A novel hybrid artificial intelligence based methodology for the inventory routing problem. Symmetry, 11, 717. https://doi.org/10.3390/sym11050717

Chen, D., Sain S. L. and Guo, K. (2012). Data mining for the online retail industry: A case study of RFM model-based customer segmentation using data mining. Journal of Database Marketing \& Customer Strategy Management, 19, 197-208. https://doi.org/10.1057/dbm.2012.17

Deb, K., Pratap, A., Agarwal, S. and Meyarivan, T. (2002). A fast and elitist multiobjective genetic algorithm: NSGA-II. IEEE Transactions on Evolutionary Computation, 6(2), 182-197. https://doi.org/10.1109/4235.996017

Deniz, A. and Kiziloz, H. E. (2017). Effects of various preprocessing techniques to Turkish text categorization using n-gram features. 2017 International Conference on Computer Science and Engineering (ss. 655-660). https://doi.org/10.1109/UBMK.2017.8093491

Dey, L., Chakraborty, S., Biswas, A., Bose, B. and Tiwari, S. (2016). Sentiment analysis of review datasets using Naive Bayes and K-NN classifier. International Journal of Information Engineering and Electronic Business, 4, 54-62. https://doi.org/10.5815/ijieeb.2016.04.07

Fan, Z.-P. Che, Y.-J. and Chen, Z.-Y. (2017). Product sales forecasting using online reviews and historical sales data: A method combining the Bass model and sentiment analysis. Journal of Business Research, 74, 90-100. https://doi.org/10.1016/j.jbusres.2017.01.010

Gaikar, D. and Marakarkandy, B. (2015). Product sales prediction based on sentiment analysis using twitter data. International Journal of Computer Science and Information Technologies, 6(3), 2303-2313.

Gezici, G. and Yanıkoglu B. (2018). Sentiment analysis in Turkish. Turkish Natural Language 
Processing. Theory and Applications of Natural Language Processing (ss. 255-271). Springer.

Jadav, B. M. and Vaghela, V. B. (2016). Sentiment analysis using support vector machine based on feature selection and semantic analysis. International Journal of Computer Applications, 146(13), 26-30.

Konak, A., Coit, D. W. and Smith, A. E. (2006). Multiobjective optimization using genetic algorithms: A tutorial. Reliability Engineering \& System Safety, $\quad 91(9), \quad 992-1007$. https://doi.org/10.1016/j.ress.2005.11.018

Kumar, K. L. S., Desai, J. and Majumdar, J. (2016). Opinion mining and sentiment analysis on online customer review. 2016 IEEE International Conference on Computational Intelligence and Computing Research (ss. 1-4). Chennaihttps://doi.org/10.1109/ICCIC.2016.791 9584

Lau, R. Y. K., Zhang, W. and Xu, W. (2018). Parallel aspect-oriented sentiment analysis for sales forecasting with big data. Production and Operations Management, 27(10), 1775-1794. https://doi.org/10.1111/poms.12737

Ozturk, Z. K., Cicek, Z. İ. E. and Ergül, Z. (2017). Sentiment Analysis: an application to Anadolu University, Acta Physica Polonica A, 132(3), 753-755.

https://doi.org/10.12693/APhysPolA.132.753

Pai, P.-F. and Liu, C.-H. (2018). Predicting vehicle sales by sentiment analysis of Twitter data and stock market values. IEEE Access, 6, 57655-57662. https://doi.org/10.1109/ACCESS.2018.2873730

Popović, D., Vidović, M. and Radivojević, G. (2012) Variable neighborhood search heuristic for the inventory routing problem in fuel delivery. Expert Systems with Applications, 39(18), 13390-13398.

https://doi.org/10.1016/j.eswa.2012.05.064
Rani, S. and Singh, J. (2017). Sentiment analysis of tweets using support vector machine. International Journal of Computer Science and Mobile Applications, 5(10), 83-91.

Sarkar, D. and Modak, J. M. (2005). Pareto-optimal solutions for multi-objective optimization of fedbatch bioreactors using nondominated sorting genetic algorithm. Chemical Engineering Science, 60, 481-492. https://doi.org/10.1016/j.ces.2004.07.130

Schneider, M. J. and Gupta, S. (2016). Forecasting sales of new and existing products using consumer reviews: A random projections approach. International Journal of Forecasting, 32(2), 243-256.

https://doi.org/10.1016/j.ijforecast.2015.08.005

Swain, A. K. and Cao, R. Q. (2019). Using sentiment analysis to improve supply chain intelligence. Information Systems Frontiers, 21(2), 469-484. https://doi.org/10.1007/s10796-017-9762-2

Thelwall, M., Buckley, K. and Paltoglou, G. (2012). Sentiment strength detection for the social Web. Journal of the American Society for Information Science and Technology, 63(1), 163-173. https://doi.org/10.1002/asi.21662

Yu, X., Liu, Y., Huang, J. X. and An, A. (2012). Mining online reviews for predicting sales performance: A case study in the movie domain. IEEE Transactions on Knowledge and Data Engineering, 24(4), 720-734. https://doi.org/10.1109/TKDE.2010.269

Yusoff, Y., Ngadiman, M. S. and Syntetos, A. M. (2011). Overview of NSGA-II for optimizing machining process parameters. Procedia Engineering, 15, 3978-3983. https://doi.org/10.1016/j.proeng.2011.08.745 